Article

\title{
Research on Group Choice Behavior in Green Travel Based on Planned Behavior Theory and Complex Network
}

\author{
Junjun Zheng, Mingyuan Xu *, Runfa Li and Liukai Yu \\ Economics and Management School, Wuhan University, Wuhan 430072, China \\ * Correspondence: xm.yuan@whu.edu.cn
}

Received: 14 May 2019; Accepted: 5 July 2019; Published: 10 July 2019

check for updates

\begin{abstract}
Motor vehicle exhaust emissions have made air pollution increasingly serious in China, and advocating for the concept of green travel can help alleviate the air pollution caused by motor vehicle exhaust. Thus, the research on the green travel choice behavior of limited rational individuals in the complex social network and the evolution of group behavior is the focus of this paper. Based on the theory of planned behavior, this paper established the individual cognition-behavior model. Meanwhile, an interaction model of individuals in the network is constructed based on the DeGroot model and scale-free network. The simulation results of the model show that: (1) it is difficult to control the behavior of green travel: even if the knowledge level of green travel is high, the proportion of green travel individuals in the group is still very low; (2) the individual intention for green travel is dependent on behavioral attitude, which can effectively improve the proportion of green travel individuals; (3) if the individual intention is too dependent on the subjective norm and the perception of behavioral result, the proportion of green travel individuals would become lower; and (4) when the network is connected, the proportion of individuals who choose green travel will reach the peak through social interaction and learning. This study has a certain practical significance for the environmental protection work of relevant departments, which can guide the behavior of individuals through the design of government institutions, and enable the concept of green travel to form an ideology by means of education and knowledge dissemination, so as to generate some kind of consensual behavioral consciousness. Meanwhile, this study provides a new research perspective for behavioral research and extends the research scope of group behavior.
\end{abstract}

Keywords: green travel; group choice behavior; planned behavior theory; scale-free network; propagation dynamics

\section{Introduction}

With the acceleration of China's urbanization process, air pollution has become more serious, and the level of pollution has reached a point which cannot be underestimated. It is necessary for the government to integrate environmental protection into China's sustainable development process. Although the government and related enterprises increase investment in the research and development of electric vehicles and other new energy vehicles to solve the serious air pollution caused by motor vehicle exhaust, the current cost of electric vehicles, which have not been popularized, is relatively high. Before the era of new energy-powered vehicles, promoting the concept of green travel can help to alleviate air pollution caused by vehicle exhaust and improve air quality. The so-called green travel refers to the individuals' travel behavior, which objectively achieves the effect of reducing the emission of polluted gases by walking, cycling, taking the subway, bus and other modes under the premise of having a motor vehicle [1]. The connotation of green travel is consistent with low-carbon travel. 
The idea of low-carbon travel is to take the travel mode with minimal impact on the environment as far as possible, save energy, improve energy efficiency, reduce emissions, be beneficial to health, and give consideration to efficiency [2]. There are some studies that have researched how to promote green travel via traffic system design. For example, the scholars Avci et al. [3] designed battery replacement station systems to expand the use range of electric vehicles and reduce their cost, thereby promoting the use of electric vehicles, and ultimately achieving the reduction of carbon emissions and dependence on oil resources. Shu et al. [4] designed and developed a practical public bicycle sharing system, using the network traffic model to estimate the number of bicycles in the network, and carried out numerical analysis to regularly redistribute the number of bicycles in the network based on Singapore bus data, thus effectively improving the effectiveness of the public bicycle sharing system. However, there are few references considering the stochastic change of individual choice behavior and the dynamic evolution of group choice behavior. Thus, promoting the concept and behavior of green travel is the focus of this paper.

The theory of planned behavior (TPB) is the study of behavior model based on the hypothesis of limited rational man [5], which is developed from the theory of reasoned action (TRA) based on the hypothesis of rational man [6]. Since the research hypothesis of "rational man" has been changed to "limited rational man", which is closer to reality, TPB has been applied to analyzing the behavior of limited rational man in various fields, including green travel. In addition, the logistic function has excellent property, that is, whatever the input is, the output calculated by the logistic function is a probability, so it is used to represent the probability of behavior in this paper.

Moreover, individuals who often have social attributes in real life are not isolated but are linked with other individuals, organizations, etc. The connections among individuals construct a topological structure of the social relationship, then an internally interrelated group is formed. Due to the existence of internal relevancy, group behavior shows a certain complexity. This kind complexity can be described by complex networks which are classified into small world networks and scale-free networks according to different statistical characteristics. Since a few individuals have a large number of connections, while most individuals have only a few connections in a social network, which is more in line with the characteristics of scale-free networks, in order to be closer to the social network in the real world, the scale-free network is more suitable to study the topic in this paper. Moreover, due to limited rationality, individuals can imitate and learn from their neighbor in the social network, so this kind of interaction can be described by the Degroot model, which is a useful tool to model the spread of information in the network.

Based on this, this paper will discuss the internal mechanism of individual behavior, and establish the relationship among individuals to explore the evolution law of group behavior by simulation experiments, in order to draw valuable conclusions for system design which can guide the group choice behavior effectively. Moreover, the idea of green travel can become an ideology through ideological education, knowledge dissemination and other means, thus creating a certain behavioral consciousness with consensus, which has certain theoretical value and practical significance for the formulation of environmental protection policies in China.

The remaining parts of this paper are organized as follows: Section 2 introduces relevant research by literature review, and in Section 3, according to the theory of planned behavior theory, the main factors influencing the intention and behavior of individuals in green travel are identified. A new individual cognitive-behavioral theoretical model is designed on the basis of the logistic function, while an interaction network model of individual choice behavior is constructed based on the DeGroot model and scale-free network. Section 4 designs the simulation experiment, including default coefficient and initial setting. In Section 5, the simulation is programmed in python, run, and the results are analyzed, respectively. In Section 6 the choice behavior for the green travel group is simulated and analyzed. Finally, Section 7 draws conclusions and discusses the future work in order to provide new ideas for the study of green travel behavior. 


\section{Relevant Research and Literature Review}

\subsection{Group Behavior}

The research on group behavior mainly focuses on two aspects. Firstly, the evolutionary game theory is used to discuss the equilibrium of group behavior achieved by all parties after dynamic game. For example, Zheng et al. [7] used evolutionary game theory to study the evolutionary characteristics of group behavior in the case of interactive information, aiming at the conflicts among groups caused by environmental pollution. Jin et al. [8] studied the problem that it is difficult to foster a synergy in regional environmental protection. By analyzing the strategic behaviors of government and social subjects, the behavior evolution mechanism of these two groups was discussed in depth. Secondly, complex network theory is used to depict the social relations among groups to explore the evolution rules of group behavior. For example, Zhao et al. [9] studied the evolution of group choice behavior in different complex social network structures based on the characteristics of social individual choice behavior with heterogeneous preferences. Liu et al. [10] researched the evolution process of action taken by vulnerable groups and powerful groups in rights-defending group events based on the characteristics of group network topology. However, there are few papers researching the evolution of group behavior in green travel, this paper can extend the research scope of group behavior.

\subsection{Theory of Planned Behavior}

As more and more attention is paid to environmental protection, the research on individual behavior in green travel is the main concern of experts and scholars in the field of social economy and management.

The theory of planned behavior is a popular theory for analyzing human behavior. According to the theory of planned behavior, the behavioral intention directly affects the behavior. The stronger the behavioral intention, the more likely the action is taken. The behavioral intention also depends on the combined effects of behavioral attitude, subjective norm and perceived behavioral control. The relationship among them is shown in Figure 1.

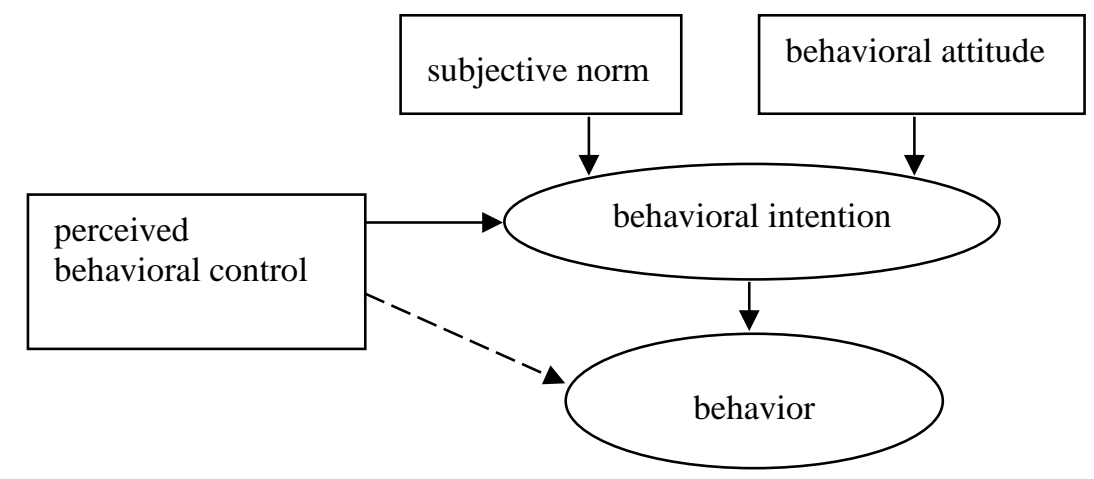

Figure 1. Theory of planned behavior [5].

According to the theory of planned behavior in Figure 1, the core factor of behavior is behavioral intention. However, behavioral intention can only affect behavior, when the individual can decide whether or not to take action. It means that an individual who is constrained by external opportunities and resources hardly has actual control over the behavior.

There are many scholars who have studied the effects of various psychological factors on individual intentions and behaviors of green travel based on the theory of planned behavior. For example, Chen et al. [11] discussed the two factors of willingness and perceived behavioral control that directly affect green travel, among which willingness plays a greater role in predicting green travel. Between the two factors of attitude and subjective norm that have a direct impact on willingness, attitude has a stronger effect on willingness. In the causal chain of green travel, the most important chain 
is "perceived effectiveness-attitude-willingness-green travel behavior"; Cui et al. [1] believed that subjective norms, behavioral attitude, perceived behavioral control, and environmental awareness are all helpful to enhance individual intention of low-carbon travel. Subjective norms indirectly affect individual intention of low-carbon travel through the mediation of behavioral attitude and perceived behavioral control. Liu [12] comprehensively studied the influencing factors of low-carbon travel of urban residents by using a non-aggregate model, utility theory, and planned behavior theory. The result shows that behavior attitude, perceived behavioral control, policy, and consumption concept all have an impact on the purchase of new energy vehicles. Bai et al. [13] showed that the informative and normative effects of reference groups had significant positive effects on individual behavior of green travel and, at the same time, functionally- and socially-perceived values had significant positive effects on individual intention of green travel, and green travel-perceived value partially or completely mediated between reference groups and individual green travel intention. Based on the theory of planned behavior, some scholars established a Multiple Indicators and Multiple Causes (MIMIC) model by adding latent variables to expand psychological variables. They used the questionnaire method to obtain samples and analyzed the correlation among the extended variables under different travel modes. The results show that not all psychological variables have a direct or indirect significant impact on intention or behavior of travel mode choice [14-16]. Most of the above studies are empirical studies, and the conclusions are mostly discussed at the individual level, with less consideration given to the influence of complex social networks on individual behavior.

\subsection{Multi-Agent Simulation}

In real life, each independent individual has a certain social relationship with each other and affects each other, then their interrelationship will form a complex social network. Due to the complexity of network structure, multi-agent simulation of individual behavior in complex social networks is a conventional research method. However, the simulation research based on the theory of planned behavior is still limited. For example: Liu et al. [17] constructed the behavior model of farmers and agricultural machinery manufacturers based on the theory of planned behavior, and used the netlogo simulation platform to simulate the individual behavior in complex social network. The result showed that government subsidy is an important factor affecting farmers' purchase of machinery, and has a significant impact on the diffusion of agricultural machinery in the group. Cui et al. [18] studied the safety production behavior of farmers. Based on the theory of planned behavior, the factors affecting farmers' behavior were determined, meanwhile the fair psychological factors and an interactive network formed by a farmer and four neighbors were considered. Then a simulation was run on the netlogo platform. The simulation results showed that farmers' endowment, punishment intensity, production organization mode, and production scale all had an impact on the farmers' behavior.

Based on the above, in order to make the research closer to the real world, we learned from the research ideas of Jiang et al. [19] and Wei et al. [20], constructing the model by using intelligent individuals and social networks to study the evolutionary process of group interaction behavior. From the perspective of individuals and groups, we integrate individual cognition and behavior into the analysis framework of a group interaction network, and simulate to study the group green travel choice problem.

\section{Modeling}

The model in this paper mainly consists of two parts: Firstly, based on the theory of planned behavior and individual bounded rationality, this paper constructs an individual choice behavior model, and analyzes the interactive mechanism between cognition and choice behavior. Secondly, when individuals are set as nodes, a social network is constructed to study the dynamic evolution process of group choice behavior in green travel. 


\subsection{Individual Choice Behavior Model}

In real life, individual choice for green travel is affected not only by self-factors and external factors, but also by the perception of behavioral result. Previous studies have shown that the perception of the behavioral result has a callback effect on green travel behavior and intention, and the corresponding perception of the result is mainly reflected in three aspects: economic savings, mental satisfaction and health improvement [21]. Based on the analysis above, according to the actual situation, this paper analyses the influencing factors of behaviors in the choice for green travel, and establishes the conceptual model shown in Figure 2.

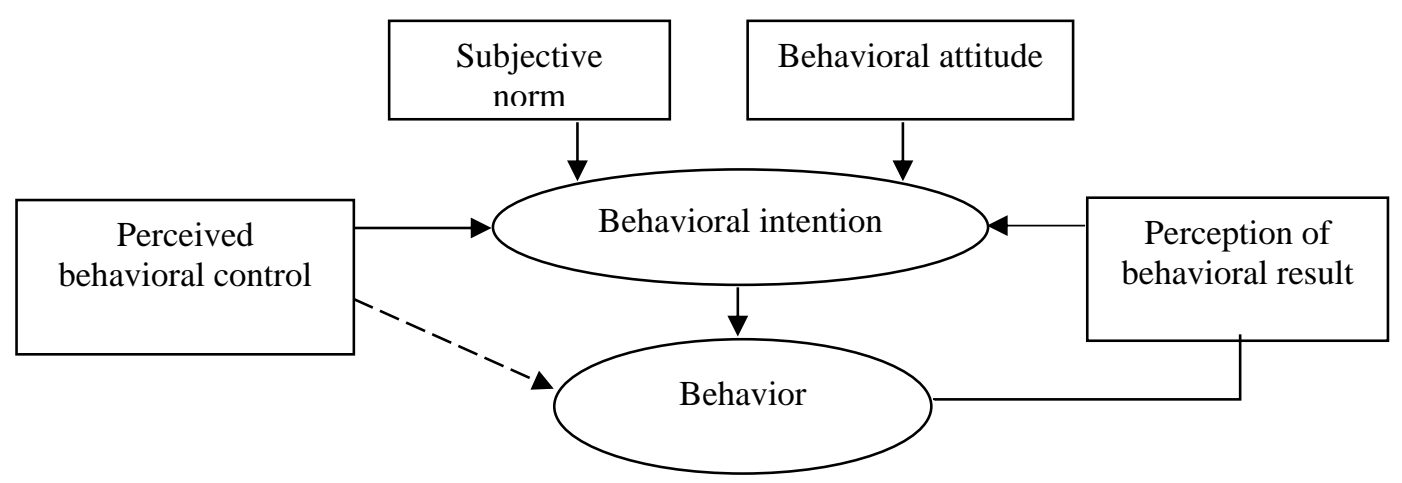

Figure 2. Conceptual model [21].

Based on the conceptual model and the influencing factors above, the individual choice behavior model is composed of a cognitive function and a behavioral function. Since individuals have bounded rationality, their cognitive function and behavioral function will change with time. Therefore, the parameters of the model are set as follows:

1. $\quad t$ : represents time and $t \in N^{+}$.

2. $\quad i$ : represents individual and $i \in N^{+}$.

3. $R_{i}(t)$ : represents the subjective norm that will make individuals receive pressure from others [13]. Imagine that when most of neighbors are traveling green, the individual will feel certain pressure from a moral level. For example, the large amount of pollution by the use of traditional motor vehicles will cause damage to the health of others, thus, the individual will feel guilty. This kind of pressure will make the individual want to get rid of the dilemma as soon as possible and enhance his intention to travel green. Thus, their impact on individual choice behavior is positive, and changes with time in the social network.

4. $K_{i}(t)$ : represents individual knowledge used to describe attitude, and the level of individual knowledge changes with time. Individual attitude has a positive impact on individual choice behavior and it is mainly affected by individual, social, and environmental factors, such as experience, education level, culture, customs, information, etc. [22]. It implies a common characteristic of individual knowledge, that is, individual experience, education, cultural customs, and related information are all important manifestations of individually-possessed knowledge. At the same time, relevant studies have verified that individual knowledge about the environment can change their behavioral attitude through empirical analysis [23]. Therefore, this paper will use the knowledge level to describe the individual attitude. Relevant knowledge about green travel includes the understanding about the role that green travel can play in improving the environment, the profound understanding of the current air pollution level, etc.

5. $\Delta_{i}$ : represents the perceived behavioral control, which is a description about the perception of the controllable degree of individual choice behavior. It reflects the individual personality characteristics, including academic qualifications, family income, etc., which are greatly affected by the exogenous objective conditions. When an individual believes that he has the necessary 
opportunities and resources to choose green travel behavior, the behavioral intention of green travel will increase with the enhancement of perceived behavioral control, that is, the influence path is "perceived behavioral control-behavior intention-behavior". However, when individuals do not have the necessary opportunities and resources to choose green travel behaviors, it is difficult to choose green travel behaviors even if they have a strong intention to choose green travel. Since this situation is simple, it is not considered in this model. The perceived behavioral control is relatively fixed in a certain period of time as it is determined by factors outside the model. In order to describe reality more accurately, $\Delta_{i}$ is set as a constant between $[-1,0)$ in the model.

6. $G_{i}(t)$ : represents perception of behavioral result. The behavioral result at the previous moment will have a positive impact on individual choice behavior at the next moment, that is, the stronger perception of behavioral result, the more likely individual green travel behavior will occur. For the convenience of calculation, we regard the expectation of behavioral result at previous moment as the perception of behavioral result at next moment (see items 8 and 9 for the definition of $f_{i}(t-1)$ and $\left.D_{i}(t-1)\right)$ :

$$
G_{i}(t)=E\left(D_{i}(t-1)\right)=f_{i}(t-1)
$$

7. $\operatorname{con}_{i}(t)$ : represents cognitive function, which is composed by the influencing factors of individual choice behavior. According to the research of Liu et al. [17], Cui et al. [18], and in order to facilitate this research, it is assumed that these factors are independent of each other. $\beta$ is the weight coefficient of the influencing factors and $\beta \in(0,1)$. The cognitive function is established as:

$$
\operatorname{con}_{i}(t)=\Delta_{i}+\beta_{f} \cdot G_{i}(t)+\beta_{R} \cdot R_{i}(t)+\beta_{K} \cdot K_{i}(t)
$$

In the formula above, $\beta_{f}, \beta_{R}, \beta_{K}$ are the weight coefficients and satisfy $\beta_{f}+\beta_{R}+\beta_{K}=1$, which represent the weighted value of the individual behavioral result perception, the green travel knowledge and the subjective normative effects, respectively.

8. $f_{i}(t)$ : represents behavioral intention which influenced individual green travel behavior, which is a probability. On the basis of logistic function [24], it is specifically expressed as:

$$
f_{i}(t)=\frac{1}{1+e^{-\alpha \cdot \operatorname{con}_{i}(t)}}
$$

In the formula above, $\alpha$ is the correction factor and $\alpha>0$, which is to make the range of $f_{i}(t)$ as wide as possible and guarantee the weight characteristics of $\beta_{f}, \beta_{R}, \beta_{K}$ at the same time. As can be seen from the Equations (2) and (3), at time $t$ individual behavioral result perception $f_{i}(t-1)$, knowledge of green travel $K_{i}(t)$, subjective norm effect $R_{i}(t)$ subjecting to the reference group and individual perceived behavioral control $\Delta_{i}$ jointly affect individual travel intention $f_{i}(t)$ at time $t$, and the influences are all positive.

9. $D_{i}(t)$ : represents strategy space about behavior choice of individual that is fgreen travel, not green travel\}. It represents the travel situation of individual $i$ at time $t$ and obeys to Bernoulli distribution and it is expressed by a $0-1$ variable, where $D_{i}(t)=1$ indicates that the individual chooses green travel and $D_{i}(t)=0$ indicates that the individual does not choose green travel. The behavior of individual $i$ on selecting green travel or not at time $t+1$ is determined by the individual green travel intention at time $t$, then it is shown as:

$$
P\left(D_{i}(t)=k\right)=f_{i}(t)^{k} \cdot\left(1-f_{i}(t)\right)^{1-k}, k=0,1
$$

That is to say, the probability of green travel at time $t$ is $f_{i}(t)$, and the probability of not green travel is $1-f_{i}(t)$. So the expected value of $D_{i}(t)$ is: 


$$
E\left(D_{i}(t)\right)=f_{i}(t)
$$

\subsection{Interaction Model Based on Scale-Free Network}

Since each individual lives in society and contacts with each other to exchange information and ideas through social network. In this paper, knowledge dissemination and influence of the subjective norm from others are both happened on the social network.

\subsubsection{The Construction of a Scale-Free Network Model}

A social network is generally a scale-free network, denoted as $C$ and expressed in the form of an adjacency matrix: $C=\left\{c_{i j}\right\}, i, j \in\{1,2, \ldots, n\}$. There are $\mathrm{n}$ nodes in $C$. Each node represents an individual, and $c_{i j}$ only takes 0 or 1 . When $c_{i j}=1$, it means that node $i$ in the network is connected with node $j$, that is, individual $i$ is a neighbor of individual $j$. When $c_{i j}=0$, it means that node $i$ and node $j$ are not connected, that is, individual $i$ is not the neighbor of individual $j$. Suppose $c_{i j}=c_{j i}$ and $\sum_{j \neq i} c_{i j}>0, j=1,2, \ldots, n$, that is, the network is an undirected graph and there is no point with degree 0 .

In order to show the relationship among individuals, a scale-free network model based on individual choice behavior is shown in Figure 3. Thus, there are two kinds of individual in a group depending on the two strategies. Especially, a circle point represents a single individual who travels in green and a triangle point represents an individual who does not choose green travel.

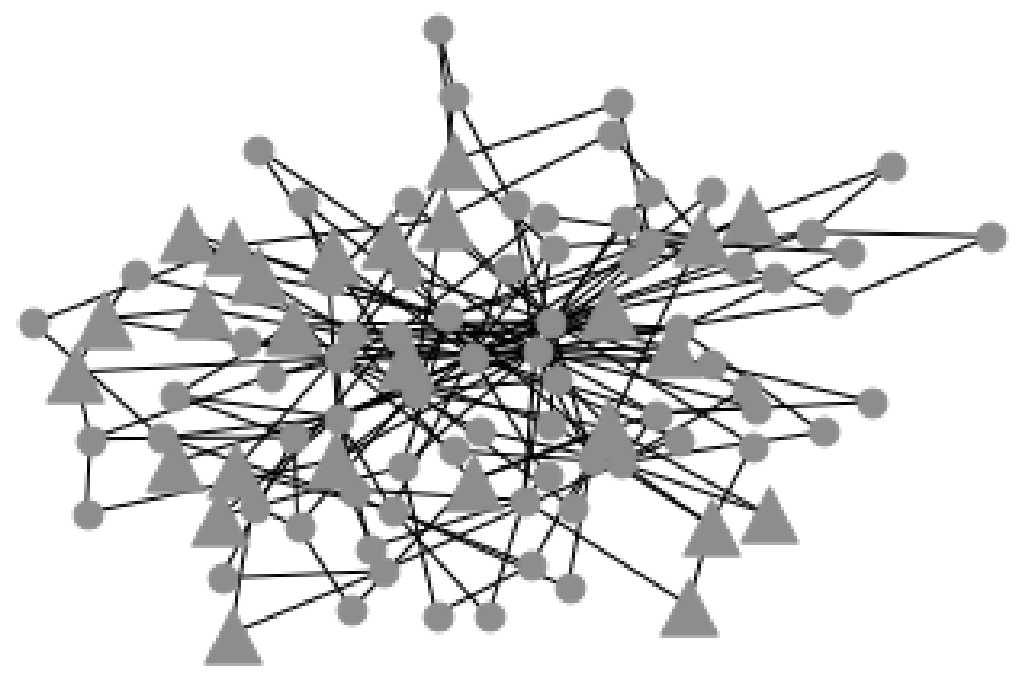

Figure 3. Diagram of individual choice behavior in the interaction model based on a scale-free network.

\subsubsection{The influence of Subjective Norms}

For individual $i$ in network $C$, the influence of a subjective norm at time $t$ can be described that individual $i$ is affected by travel conditions of its neighbors. Thus, we use the proportion of green travel neighbors in the total neighbors at time $t$ to represent the influence of the subjective norm on individual $i$ at time $t$. Namely:

$$
R_{i}(t)=\frac{\sum_{j \neq i} c_{i j} \cdot D_{j}(t)}{\sum_{j \neq i} c_{i j}}
$$

As can be seen from the formula above:

1. $0 \leq R_{i}(t) \leq 1$

2. At time $t$, the more neighbors of individual $i$ travel in green, the greater subjective normative effect $R_{i}(t)$ is. 


\subsubsection{The Rule of Knowledge Dissemination}

This paper assumes that the dissemination of knowledge in the network is the main way for individuals to acquire knowledge about green travel. According to the actual situation, in real life, non-professionals can only make subjective exploration of air pollution and automobile exhaust by their own knowledge without resorting to information tools such as the network or making offline communication with others, and they do not have objective conditions for deep exploration. In most cases, individual knowledge of air pollution and green travel is mostly acquired through the network, especially in terms of objective statistical data, whether on-line or off-line.

With regard to the dissemination of knowledge about green travel in the network, this paper draws on the idea of the DeGroot model [25] and adjusts it accordingly to make the model more realistic. According to the definition in Section 3.1., the green travel knowledge of individual $i$ at time $t$ is $K_{i}(t)$, and let $K_{i}(t) \in[0,1]$. The higher value represents that the individual gets more objective and accurate understanding in green travel, thus there is more possibility to travel green. In the period of time $[t, t+1]$, individual $i$ has a certain probability to communicate with its neighbors, so that their knowledge has a certain probability to be improved. In this paper, the rules of knowledge promotion in social networks are set as follows:

1. In the period of time $[t, t+1]$, each individual in the network communicates with its neighbors in probability $p$. The communication between individuals and neighbors does not affect each other, and the order of communication is not considered.

2. If individual $i$ communicates with its neighbor $j$ successfully in the period of time $[t, t+1]$, when $K_{i}(t)>K_{j}(t)$, the knowledge of individual $i$ remains unchanged.

3. If individual $i$ communicates with its neighbor $j$ successfully in the period of time $[t, t+1]$, when $K_{i}(t) \leq K_{j}(t)$, individual $i$ gains knowledge about green travel, and the amount of knowledge increment is $\frac{1}{\sum_{j \neq i} c_{i j}}\left[K_{j}(t)-K_{i}(t)\right]$.

According to the rules of knowledge promotion, it can be shown as below:

$$
K_{i}(t) \leq K_{i}(t+1) \leq \max _{j=1,2, \ldots, n} K_{j}(t)=\max _{j=1,2, . ., n} K_{j}(0)
$$

Under the condition that $K_{i}(t)$ of individual $i$ is known, the expected value of green travel knowledge at time $t+1$ is $E\left(K_{i}(t+1) \mid K_{i}(t)\right)$, which is shown as:

$$
E\left(K_{i}(t+1) \mid K_{i}(t)\right)=K_{i}(t)+\sum_{j \neq i} c_{i j} \cdot p_{c} \cdot \max \left\{\frac{1}{\sum_{j \neq i} c_{i j}}\left[K_{j}(t)-K_{i}(t)\right], 0\right\}
$$

\section{Design of the Simulation Experiment}

The environment in real life is very complex, thus, it is very difficult to model and analyze every detail. Therefore, in the framework of the model above, this paper puts individuals in a specific social network environment, and carries out simulation experiment design from a holistic perspective to explore the evolution of each variable in the network with time.

\subsection{Scale-Free Network Default Coefficient and Initial Setting}

In order to be closer to the social network in real world, this paper describes the individual social network using the BA scale-free network proposed by Barabasi and Albert in 1999 [26]. The nodes' degrees obey the power-law distribution. According to the literature on similar studies $[27,28]$, the population of a small community is around 1000. Therefore, the BA scale-free network with $N=1000$ nodes is constructed by using Barabasi and Albert methods in this paper. The degree distribution of nodes is shown in Figure 4. 


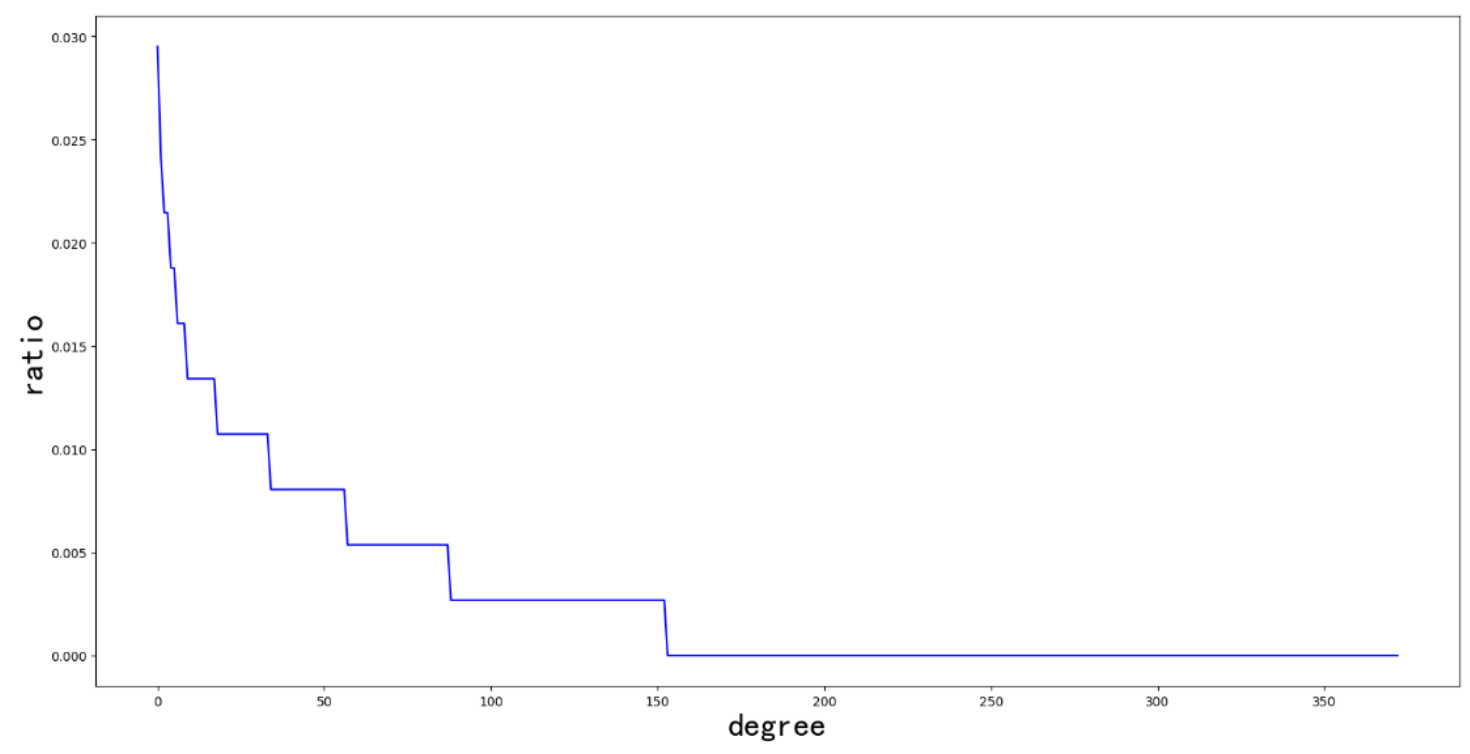

Figure 4. Scale-free network node degree distribution.

In Figure 4, the degree of most nodes is under 150 in the network. The tail of the curve in the graph looks like a straight line, which shows that the distribution of node's degree obeys the power law distribution [29].

\subsection{Default Coefficient and Initial Setting}

In order to run the numerical simulation, the default coefficients need to be set. In this paper, the principle of setting default coefficients is to maximize the impact of parameters change on the results, and to ensure the validity of the model, that is, the results are not too extreme in numerical value. With all considerations above, the default coefficients are set as follows: $\Delta=-0.5, \beta_{f}=0.3, \beta_{R}=0.4$, $\beta_{K}=0.3, \alpha=10, p_{c}=0.5$.

In the network, whether an individual has the behavior of green travel at the initial time is generated by Bernoulli distribution $B(1,0.3)$. Individual knowledge about green travel at the initial time is generated by a truncation in interval $[0,1]$ of normal distribution $N\left(0.1,0.3^{2}\right)$. After the coefficients and other initial values are determined, the individual initial intention of green travel is generated by the standard normal distribution $N(0,1)$ at first, then it is generated by putting it into Equations (2) and (3) for one iteration.

\subsection{Group Choice Behavior Setting}

In order to quantitatively express the group choice behavior in simulation experiment, this study selects the proportion of individuals who take green travel strategy in the whole as the analysis data. Let the proportion be $\rho(t)$, and the calculation formula is:

$$
\rho(t)=\frac{\sum_{i \in N} D_{i}(t)}{N}
$$

\section{Analysis and Discussion of the Simulation Experiment}

Based on the simulation experiment above, the evolution of the following variables will be carried out respectively: perceived behavioral control, behavioral attitude, subjective norm, and behavioral result perception, then the simulation results will be analyzed. 


\subsection{The Influence of Perceived Behavioral Control on Group Choice of Green Travel in Network}

The perceived behavioral control is $\Delta$, which reflects the difficulty of green travel perceived by individuals. In order to explore its influence on the proportion of green travel individuals in the group with time, the proportion of green travel individuals with different $\Delta$ is shown in Figure 5.

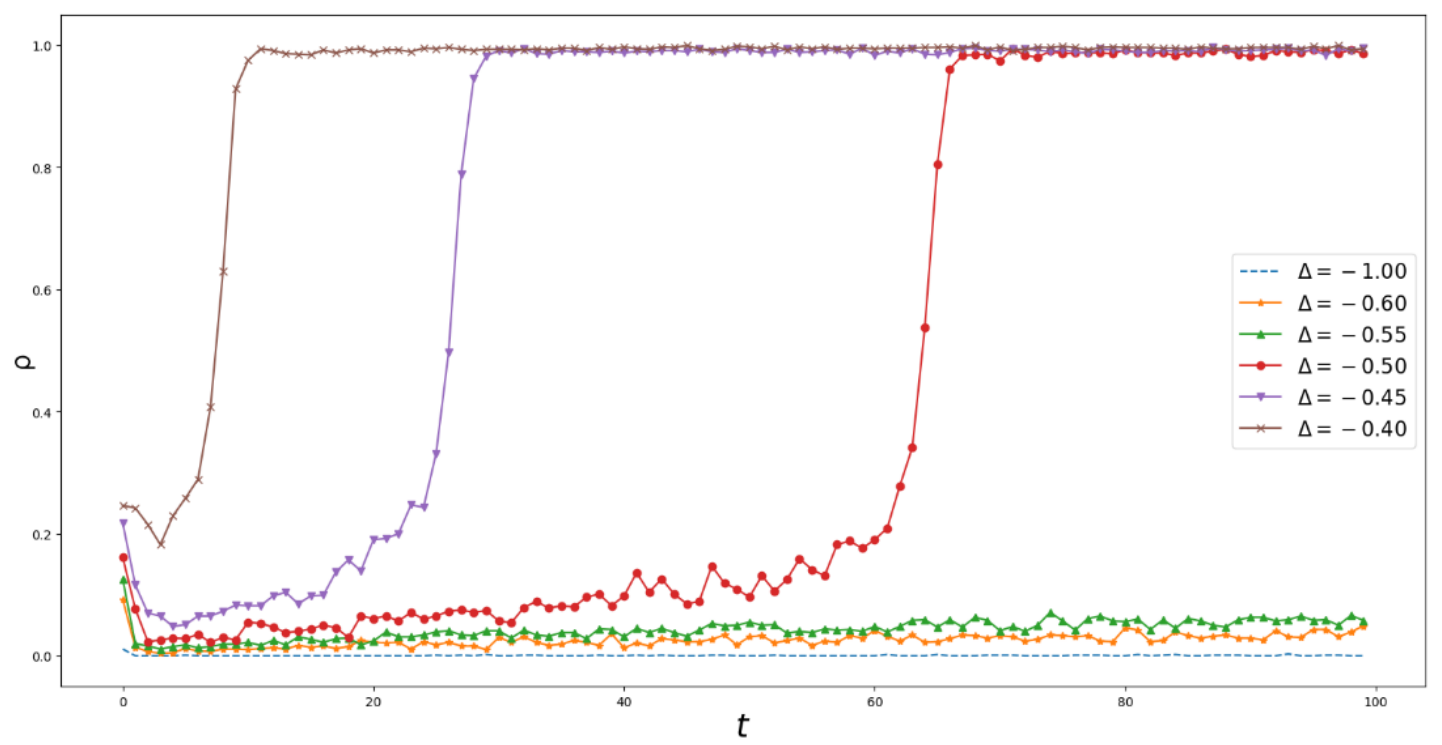

Figure 5. Individual proportion of green travel with different $\Delta$.

The influence of perceived behavioral control can be seen in the Figure 5:

1. A slight change in the value of $\Delta$ will have a significant impact on the results.

2. When $\Delta$ decreases, the proportion of green travel individuals in the group will increase slowly, and the critical point of explosive growth will move backward.

3. When $\Delta \leq-0.55$, the growth rate of proportion of green travel individuals become significantly slower, and when $\Delta=-1$, the proportion of green travel individuals remains at $0 \%$.

It can be seen that when individuals have substantial difficulties in green travel, even if they have a deep understanding of green travel, they cannot improve their intention to go green. The example in Li Yang's interview and research can well illustrate this point: although it is convenient for some families to travel by subway, they can only choose motor vehicles to drive their children to school [2].

\subsection{The Influence of Behavioral Attitude on the Group Choice of Green Travel in the Network}

Individual knowledge can change their behavioral attitude towards green travel. To be specific, the knowledge is the understanding about the green travel behavior, as well as green travel and air pollution, which can be propagated through the network. The knowledge is always spread from the individuals whose knowledge level is high to the individuals whose knowledge level is low. As long as the connectivity of network is strong enough, the spread of knowledge will eventually make the whole network maintain a high level of knowledge.

Let $\beta_{f}$ be 0 , then $\beta_{R}+\beta_{K}=1$. Now consider the influence of the change of weight $\beta_{K}$ and $\beta_{R}$ on the result.

The proportions of green travel individuals can be obtained when $\beta_{K}$ takes different values. The influence of behavioral attitude can be seen from Figure 6:

1. When the value of $\beta_{K}$ is small, such as $\beta_{K} \leq 0.3$, the proportion of individuals who travel green does not exceed $10 \%$ even after a long time. However, when $\beta_{K}$ exceeds a certain critical value, the proportion of individuals who travel green is close to $100 \%$ after a certain period of time. 
2. With the increase of time, the critical value of $\beta_{K}$ decreases continuously, about 0.3 at $t=50$, about 0.22 at $t=100$, and about 0.2 at $t=300$.

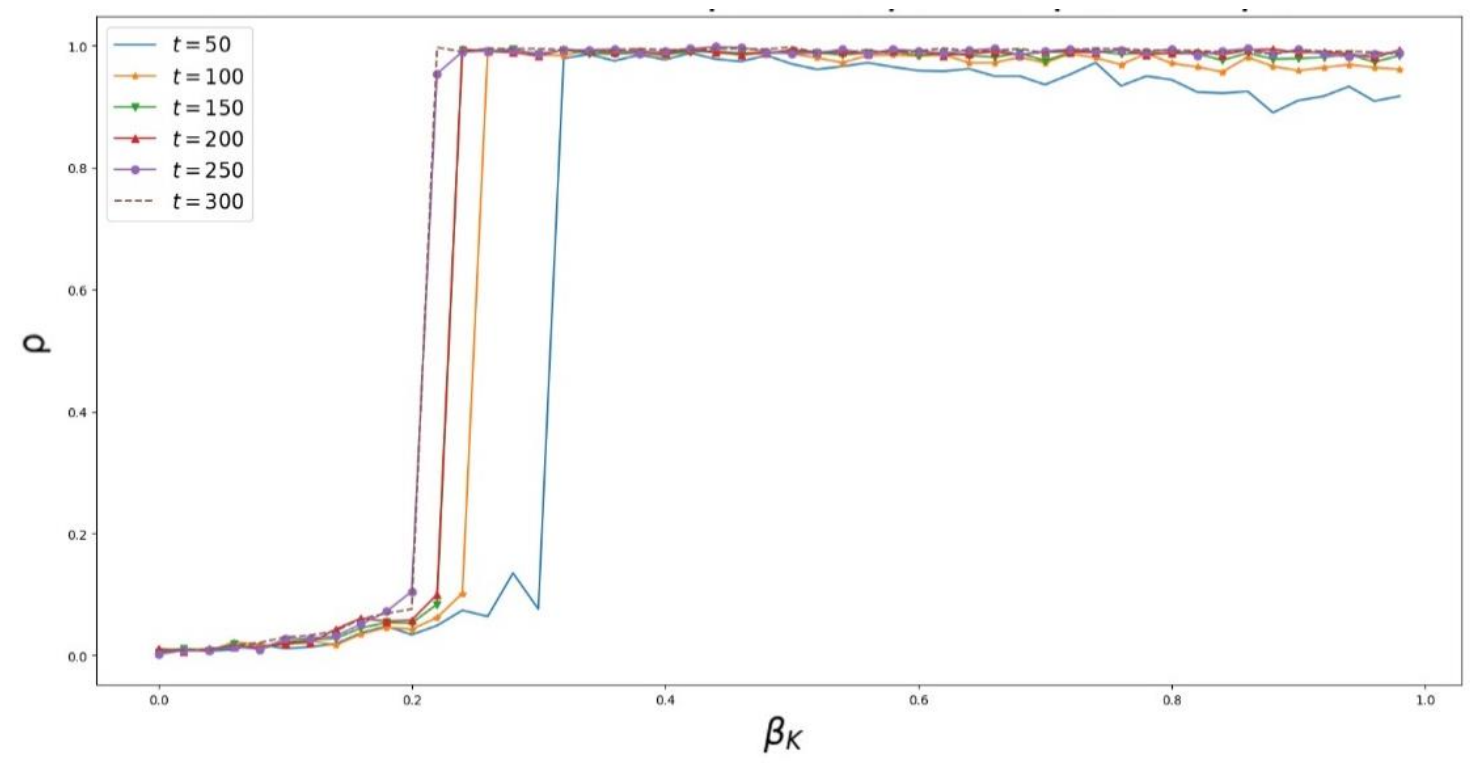

Figure 6. Individual proportion of green travel changes with $\beta_{K}$.

From the analysis above, although the dissemination of knowledge will make the knowledge level of the group in the network reach a higher level (as shown in Figure 6), the knowledge level of the group is still low if the weight $\beta_{K}$ is small. Therefore, in order to improve the knowledge level of the group effectively, we should take efforts to increase the $\beta_{K}$ of each individual in the group so that the individual intention of green travel is more dependent on behavioral attitude than subjective norms.

\subsection{The Influence of Subjective Norms on the Group Choice of Green Travel in the Network}

Let $\beta_{K}$ be 0 , which means that the green travel knowledge cannot affect individual intention, then let $\beta_{f}+\beta_{R}=1$. We explore the evolution of the proportion of green travel individuals in the network with different values of $\beta_{R}$. Results are show in Figure 7.

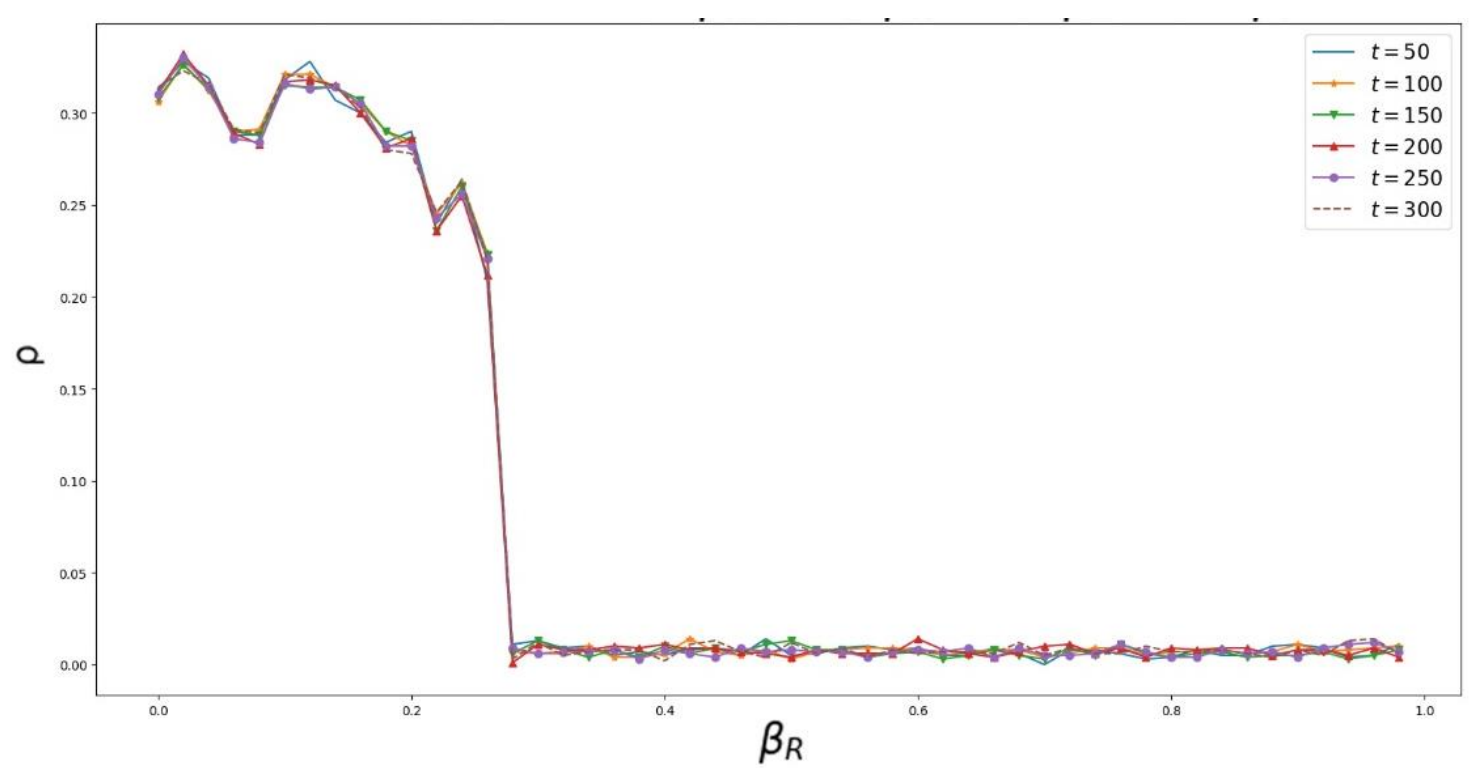

Figure 7. The proportion of individuals traveling in green varies with $\beta_{R}$. 
The influence of subjective norms can be seen from Figure 7:

1. The six curves almost coincide, indicating that the green travel level of the whole network hardly changes and remains stable;

2. The larger $\beta_{R}$ is, the lower proportion of green travel is. When $\beta_{R}$ is greater than a certain critical value, the proportion of green travel drops down to about $2 \%$.

When the proportion of green travel is low, the over-reliance on subjective norms will make the proportion of green travel become very low.

\subsection{The Influence of Behavioral Result Perception on the Group Choice of Green Travel in Network}

Since individuals will be affected by the perception of behavioral result at previous moment, which will have a positive impact on individual behavioral choice at next moment. The perception of the behavioral result in this model is regarded as the individual intention to travel at the previous moment.

In this section, $\beta_{R}$ is set to 0 , which means the subjective norm cannot affect individual intention, meanwhile, $\beta_{f}+\beta_{K}=1$. The simulation result is shown in Figure 8 .

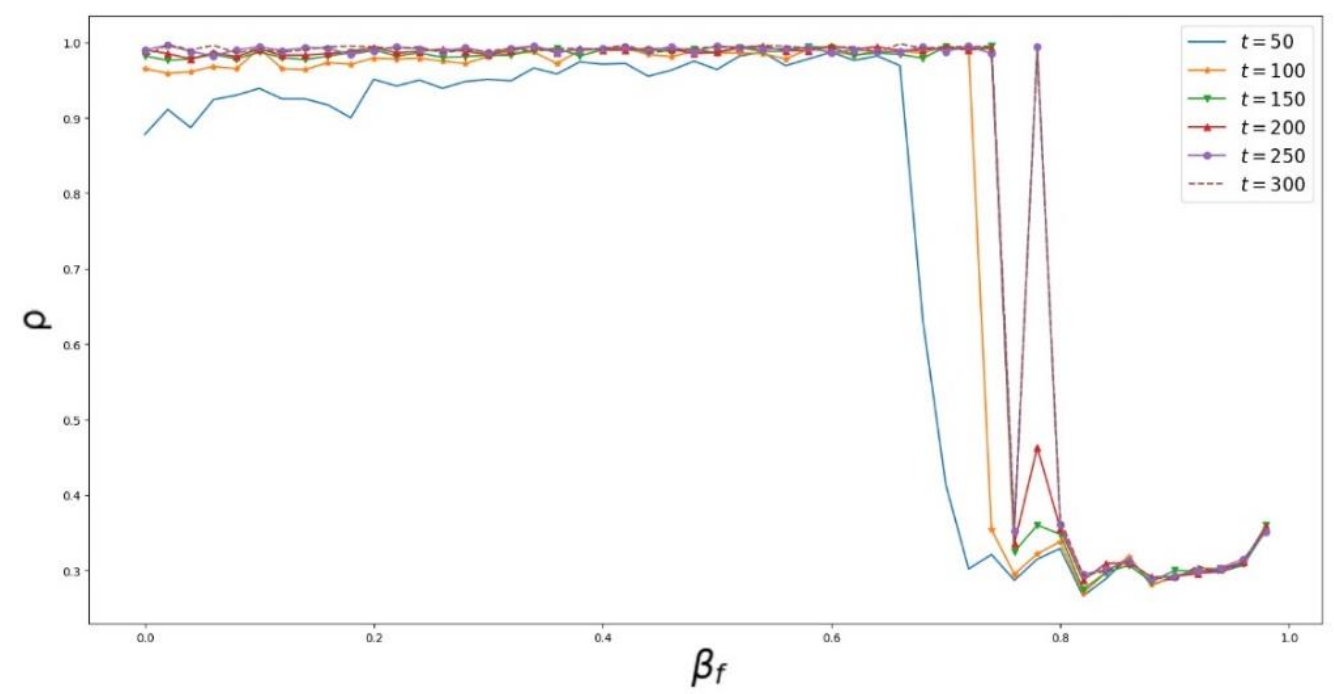

Figure 8. Individual proportion of individual traveling in green changes with $\beta_{f}$.

As can be seen from Figure 8:

1. The proportion of individual traveling green decreases with the increase of $\beta_{f}$. When $\beta_{f}$ is greater than a certain threshold, the proportion of green travel drops down to about 0.3 .

2. With the increase of time, the critical value of $\beta_{f}$ increases continuously, about 0.65 at $t=50$, about 0.75 at $t=100$, and about 0.8 at $t=300$.

The proportion of green travel individuals will decrease when the individual green travel intention depends too much on the perception of the behavior result.

\section{Analysis of Group Choice Behavior Evolution}

When the default initial value and the default coefficients are taken into simulation, the result is shown in Figure 9. In Figure 9, $\overline{D(t)}$ denotes the proportion of green travel individual in the whole group at time $t, \overline{f(t)}$ denotes the average value of individual green travel intention at time $t$, and $\overline{K(t)}$ denotes the average value of knowledge about green travel at time $t$. 


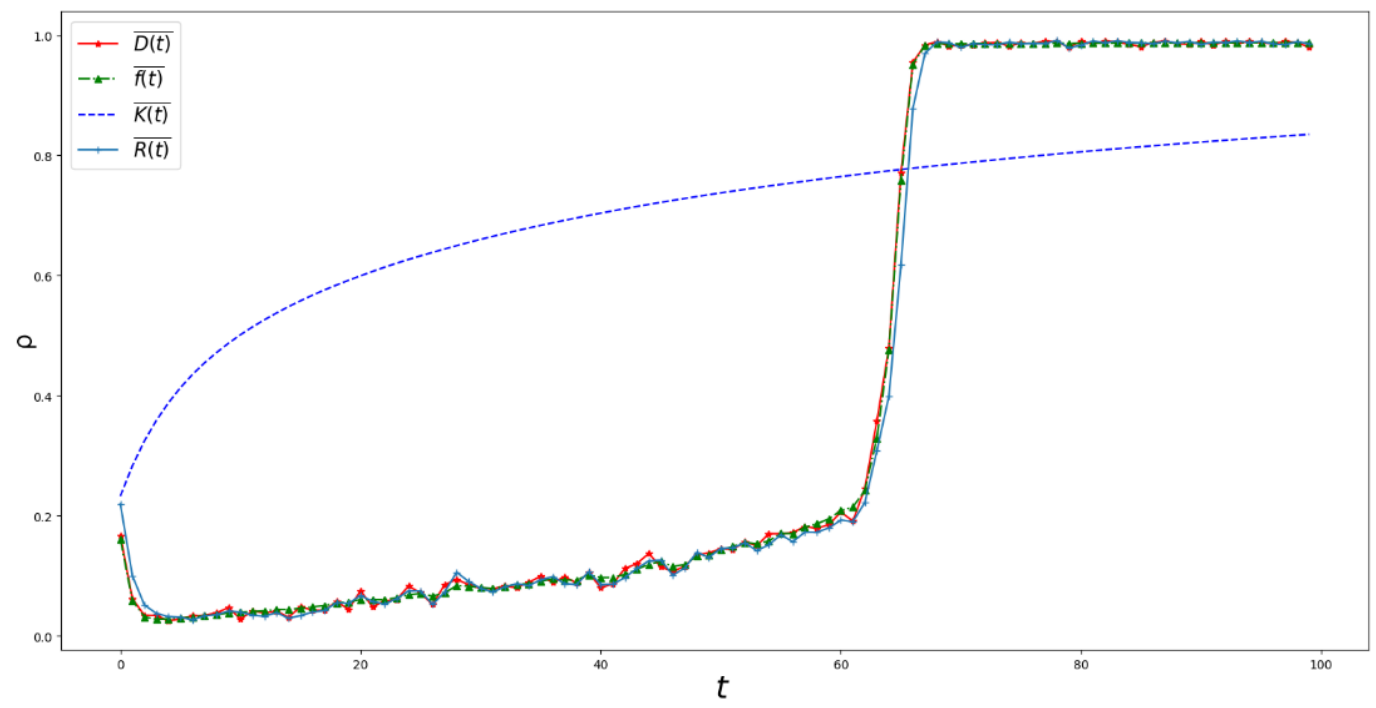

Figure 9. Simulation results under default initial values.

It can be seen in Figure 9 that the average initial knowledge of all individuals in the network is about $22 \%$, and the initial proportion of individuals choosing green travel is about $18 \%$.

1. The curve of $\overline{K(t)}$ keeps rising. when the network is connected, $\overline{K(t)}$ will eventually converge to the maximum value of green travel knowledge in the network if time is sufficient, namely: $\max _{j=1,2, . ., n} K_{j}(0)$.

2. At time around 60, the rate of green travel individuals in the group reaches a critical point, and the number of green travel individuals in the network shows an explosive growth. During that time, the changing magnitude of $\overline{K(t)}$ is far greater than the changing magnitude of $\overline{D(t)}$ and $\overline{f(t)}$, which means that the breakthrough in the number of green travel individuals is caused by the accumulation of green travel knowledge.

3. $\overline{D(t)}$ is almost identical to $\overline{f(t)}$, that is, the average intention of green travel individuals in the group is highly coincident with the proportion of green travel individuals in the group. When the network is connected, the proportion of individuals who finally choose green travel will reach the peak through social interaction and learning.

\section{Conclusions}

Based on the theory of planned behavior, this paper established an individual cognition-behavior model in which individual green travel intention is influenced by individual behavioral attitudes, perceived behavioral control, subjective norms, and behavioral result perception. Based on the DeGroot model and scale-free network, an interaction model for group choice behavior is established. Then a simulation experiment is run on a python platform and the results of the simulation are shown as follows:

1. It is difficult to control the behavior of green travel: even if the knowledge level of green travel is high, the proportion of green travel individuals in the group is still very low.

2. The individual intention for green travel is dependent on behavioral attitudes that can effectively improve the proportion of green travel individuals.

3. If the individual intention is too dependent on the subjective norms and the perception of behavioral results, the proportion of green travel individuals declines.

4. When the network is connected, the proportion of individuals who choose green travel will reach the peak through social interaction and learning. 
According to the report of the 19th National Congress, insisting on the harmonious coexistence between man and nature and building an ecological civilization are the millennium goals of sustainable development in China. Actually, green travel is also one of the green lifestyles. In the process of choosing green travel, the understanding and analysis about individual choice and group choice are of great practical significance. We can gain important enlightenment for the environmental protection work to relevant departments. The interaction among individuals and the evolution of group choice also provide a new research perspective for behavioral research. At the same time, further research of this study may include the following aspects:

1. The weights of each influencing factor can be measured by the method of behavioral experiments, which are used to analyze the behavior of homogenous and heterogeneous individuals, then the rules and trends of group choice can be studied in depth.

2. By relaxing the hypothesis that individual psychological factors are independent of each other, we can explore the influence of correlation among psychological factors on the evolution of group behavior.

Author Contributions: Conceptualization and supervision: J.Z. and M.X.; methodology: M.X. and R.L.; software: R.L.; validation: M.X.; writing—original draft preparation: R.L., M.X., and L.Y.; writing—review and editing: M.X.; project administration: M.X.

Funding: This research was funded by National Natural Science Foundation of China, grant number 71771181, which the authors appreciate for the support.

Acknowledgments: We would like to thank all relevant individuals that put forward constructive suggestions to help improving this paper.

Conflicts of Interest: The authors declare no conflict of interest.

\section{References}

1. Cui, F.; Zhang, Y. Influencing factors of urban residents' low-carbon travel intention. Urban Probl. 2017, 11, 96-103.

2. Li, Y. The analysis of influencing factors to green travel urban residents based on grounded theory. Soc. Sci. Front 2017, 6, 265-268.

3. Buket, A.; Karan, G.; Serguei, N. Electric Vehicles with a Battery Switching Station: Adoption and Environmental Impact. Manag. Sci. 2014, 61, 772-794.

4. Jia, S.; Mabel, C.C.; Liu, Q.Z.; Teo, C.P.; Wang, I.L. Models for Effective Deployment and Redistribution of Bicycles within Public Bicycle-Sharing Systems. Oper. Res. 2013, 61, 1346-1359.

5. Ajzen, I. The theory of planned behavior. Organ. Behav. Hum. Decis. Process. 1991, 50, 179-211. [CrossRef]

6. Fishbein, M.; Ajzen, I. Belief, Attitude, Intentions, and Behavior: An Introduction to Theory and Research; Addison-Wesley: Menlo Park, CA, USA, 1975.

7. Zheng, J.J.; Yan, L.; Zhang, H.Y.; He, H.Y. Disposal Mechanism of Environmental PollutionMass Incidents Based on Evolutionary Game and Optimization Theory. Chin. J. Manag. Sci. 2015, 23, 168-176.

8. Jin, S.; Du, J.G.; Sheng, Z.H. Evolutionary Game Analysis of Regional Environmental Protection Programme. Syst. Eng. Theory Pract. 2015, 35, 3107-3118.

9. Zhao, Z.L.; Chen, Z.; Sun, W.J.; Li, L. Diffusion with Property of Differential Choice in Complex Social Network. J. Manag. Sci. China 2010, 13, 38-49.

10. Liu, D.H.; Wang, W.G. Co-evolutionary Mechanism of Social Network Structure and Strategy in Mass Emergency with Maintain Legal Rights. Chin. J. Manag. Sci. 2012, 20, 185-192.

11. Chen, K.; Peng, Q. Effects of Reference Group on Attitude-behavior Gap in Green Consumption. China Popul. Resour. Environ. 2014, 24, 458-461.

12. Liu, W. Influence Factors and Guidance Strategy of Low Carbon Travel for Urban Resident in China. Ph.D. Thesis, Beijing Institute of Technology, Beijing, China, 31 December 2014.

13. Bai, K.; Li, C.X.; Zhang, C.J. Reference Group Influence and Self-Perceived Value Judgment of Xi'an Urban Residents' Green Travel Behavior. Hum. Geogr. 2017, 32, 37-46. 
14. Xu, B.; Shao, C.F.; Qian, J.P.; Li, J. Modelling for Intercity Travel Mode Choice under the Theory of Extended Planned Behavior. J. Transp. Eng. 2018, 18, 28-35.

15. Jing, P.; Juan, Z.C.; Zha, Q.F. Incorporating Psychological Latent Variables into Travel Mode Choice Model. China J. Highw. Transp. 2014, 27, 84-92+108.

16. Jing, P.; Juan, Z.C.; Zha, Q.F. Application of the Expanded Theory of Planned Behavior in Intercity Travel Behavior Based on MIMIC Model. J. Ind. Eng. Eng. Manag. 2016, 4, 61-68.

17. Liu, W.; Tong, H.Z.; Ding, K.N. Analysis of Governmental Subsidy Factors Influencing Agri-machinery Diffusion under the Background of BOP Strategy-Simulation Research Based on Multi-agent Modeling. Manag. Rev. 2017, 29, 200-212.

18. Cui, L.; Luo, L.P. Decision-making Simulation of Farmers' Safe Production Behavior. J. Syst. Simul. 2018, 30, 1347-1360.

19. Jiang, G.Y.; Ma, F.C. Evolution of interactive behavior in collaborative e-commerce. J. Manag. Sci. China 2016, 19, 1-12+126.

20. Wei, X.C.; Li, Y.F.; Nie, G.H.; Chen, D.L. Research on Consumer Decision-making Interaction Behavior in New Product Diffusion Based on Regret Theory and Multi-Agent Simulation. Chin. J. Manag. Sci. 2017, 25, 66-75.

21. Yang, R.R.; Long, R.Y. Study on Driving Mechanism and Policies of Urban Residents' Green Travel Behavior. Ph.D. Thesis, China University of Mining and Technology, Xu Zhou, China, May 2016.

22. Zhang, T.; Nuttall, W.J. Evaluating Government's Policies on Promoting Smart Metering Diffusion in Retail Electricity Markets via Agent-based Simulation. J. Prod. Innov. Manag. 2011, 28, 169-186. [CrossRef]

23. Sabine, D.; Stuart, H.L. The environmental value-attitude-system model: A framework to guide the understanding of environmentally conscious consumer behavior. J. Mark. 1994, 10, 593-603.

24. Damodar, N.G.; Dawn, C.P. Basic Econometrics, 5th ed.; China Renmin University Press: Beijing, China, 2016.

25. Jackson, M.O. Social and Economic Networks; Princeton University Press: Princeton, NJ, USA, 2010.

26. Barabasi, A.L.; Albert, R. Emergence of Scaling in Random Networks. Science 1999, 286, 509-512. [PubMed]

27. Damon, C. The Spread of Behavior in an Online Social Network Experiment. Science 2010, 329, $1194-1197$.

28. Damon, C. An Experimental Study of Homophily in the Adoption of Health Behavior. Science 2011, 334 , 1269-1272.

29. Downey, A.B. Think Complexity; Oreilly Vlg Gmbh \& Co.: Sebastopol, CA, USA, 2012. 